\title{
Economic, technical and environmental aspects of fuel additive ENVIROX during trials with diesel engines
}

\author{
J. Mares ${ }^{1}$, F. Božek ${ }^{1}$, P. Krizek ${ }^{1}$, V. Zajicek ${ }^{1}$ \& L. Maresova ${ }^{2}$ \\ ${ }^{1}$ Logistics Department, University of Defence, Czech Republic \\ ${ }^{2}$ Masaryk University in Brno, Czech Republic
}

\begin{abstract}
This paper is an assessment of fuel consumption reduction due to the application of additive ENVIROX. Evaluation of economic benefits depending on engine load is also discussed in this paper. Furthermore, the influence of additives on the structure of selected engine parts, especially injection pumps, valves, combustion chambers, pistons and piston rings is assessed. The possible changes are monitored and compared before and after the long term trial. There is presented the influence of fuel additives to the environmental burden by some controlled emission components of exhaust gases also.

Keywords: additive, oxide cerium, nanoparticles, economic benefits, changes in shape and dimensions of selected engine parts, tribodiagnostics analysis, components of the exhaust gases.
\end{abstract}

\section{Introduction}

With advancing civilization the society development is related to the technical progress. In its favor, it is necessary to cover energy costs, the trend can be miniaturized devices; cost reduction, increased equipment efficiency and lower energy consumption. All potential benefits are welcome, especially new technologies in section of rotating machines such as internal combustion engines. To their greater efficiency can also contribute new products from the field of nanotechnology.

Important position in industry, agriculture and supply to individuals and businesses has transportation. It is inextricably linked to fuel consumption. This has had an excessive growth in the Czech Republic; the consumption is between 
8-10 billion of fuel (petrol and diesel) per year. Higher consumption than Czech Republic has Germany with 40 billion liters per year, France with 38 billion liters, Spain with 28 billion liters and Great Britain with 27 billion liters of fuel [1]. Transport and the operation of vehicles in addition to the need of their use bring a number of negative impacts. This implies to increasing of the atmosphere load and operational waste management. With high transportation dynamics is also related the fact, that given problem has insufficient attention and the increase in emission status is a social threat which intensely dealt with the world's cities [2-4]. Well known is the growing imbalance between on road and rail transport and the use of personal vehicles at the expense of means of public transportation $[5,6]$.

It is estimated that transport contributes to the overall air pollution by carbon monoxide $(\mathrm{CO})$ and carbon dioxide $\left(\mathrm{CO}_{2}\right)$ by $37 \%$, by mixture of nitric oxide and nitrogen dioxide (NOx) by $30 \%$, and volatile organic compounds (VOCs), by approximately $24 \%$ [7]. Hazardous waste is produced during the vehicle operation as well as during accidents and at the end of their life cycle.

The present time is notable in finding ways to savings and reducing costs in all departments and especially in transport. Possible solution is the use of additives and their effects. The selected additive may affect the safe operation and durability of the equipment in operation [8]. Furthermore it has an impact on economic indicators such as reduction in fuel consumption and expression of decreased economic costs, including purchase of additive, its dosing and transport [9].

This article is focused on the overall assessment of additive influence on the operation capability, safety and cost of engine running. There are considered main parameters of engine, state of measured engine parts, properties of additive ENVIROX $^{\mathrm{TM}}$, additive fuel in its use, fuel system status, emissions of gaseous and particulate engine pollutants, conditions and quality of oil. Storage of fuel Envi NM 54 and additive Envirox itself is also addressed in the paper.

\section{The analysis of current state}

The amount of pollutants emitted while driving a motor vehicle is dependent on many factors. If the movement, typical for each driver is left aside, as well as the nature of terrain and weather conditions, the current emissions are produced bounty of feature in particular.

When is vehicle operating there are individual elements of the crank mechanism worn out. The wear degree and the cooling efficiency depend on the type and quality of engine oil and other operational fluids. Their quality is assessed by analytical methods. Verification of features and quality of engine oil is realized by tribodiagnostics analysis. Based on analyzed parameters of engine oil it is possible to detect real condition of evaluated vehicles (machines). Whether there is serviceable, limit or critical condition.

Oil samples are taken according to established methodology or in case of any suspected non-standard behavior of the monitored equipment. Implementation analysis of samples consists of evaluating the results and their sending to the user 
with information about the outcome and recommendations for further action. Complete vehicle tracking methods of tribotechnical diagnosis involve three basic groups of parameters. These are operation-economical indicators - total vehicle run over; quantitative indicators - represents concentration of elements in $\left[\mathrm{mg} \cdot \mathrm{kg}^{-1}\right]$, and qualitative indicators such as kinematic viscosity, fuel volume in oil, volume of nitration parts, volume of antioxidants and anti-wear additives etc. [10]. Similar and very sophisticated program of oil analysis have foreign partners in U.S. It is used mainly in military conditions under the name AOAP (army oil analysis program). Analyses are performed by stationary and mobile laboratories [11].

The additives for improvement of technical parameters and increase of engine performance are dispensed into the diesel fuel by the end user at the distribution terminal of later into the storage reservoir or directly to the fuel tank. Universal and logically usable appear to be additive Envirox ${ }^{\mathrm{TM}}$, which is a diesel fuel type of additive. It is, according to Energenics Company (formerly Oxonica), suppose to improve not only technical parameters of fuel but brings other benefits in comparison with conventional additives in this group [18].

Envirox ${ }^{\mathrm{TM}}$ is dispersion of $\mathrm{CeO}_{2}$ nanoparticles in aliphatic cyclo-aliphatic hydrocarbons. Unlike other conventional additives, it is said to be effective throughout the entire combustion process because due to the thermodynamic conditions prevailing in the combustion chamber of the engine most of common ingredients decay. The additive enables to obtain more energy from fuel and to reduce its consumption, remove the rest of soot deposits in the engine combustion and while minimizing the creation of some contaminants $[18,19]$. Chemical processes are presented in equations in [24]. $\mathrm{CeO}_{2}$ catalyst regeneration takes place according to the formulas in [24] and according to the final equation (1).

$$
4 \mathrm{Ce}_{2} \mathrm{O}_{3}+\mathrm{O}_{2}=2 \mathrm{CeO}_{2}
$$

The amount of emissions produced by moving vehicle is among others based on factors such as engine type and specification, the principle of oxidation catalyst activity [21], type and amount of biodiesel added to the base fuel, composition and quality of diesel used [22] and type and composition of additives in the base fuel.

$$
E f_{m}^{i}=m_{i} \times m_{F}{ }^{-1}=y_{i}^{d} \times \frac{M_{i} \times n^{d}}{M_{F} \times N_{F}}
$$

The calculation of emission of $\mathrm{i}^{\text {th }}$ pollutant is based on the knowledge of value of emission factor $E f_{m}^{i}\left[\mathrm{~g} \mathrm{~kg}^{-1}\right]$, which is in compliance with the relation (2) in [24] given by mass of $i^{-}{ }^{\text {th }}$ pollutant relative to mass unit of consumed fuel. Where $\mathrm{m}_{\mathrm{i}}[\mathrm{g}]$ is the mass of $i^{\text {th }}$ pollutant, $\mathrm{m}_{\mathrm{F}}[\mathrm{kg}]$ mass of consumed fuel, $\mathrm{M}_{\mathrm{i}}$ molar molecular mass of $\mathrm{i}^{\text {th }}$ pollutant $\left[\mathrm{g} \mathrm{mol}^{-1}\right], \mathrm{M}_{\mathrm{F}}\left[\mathrm{kg} \mathrm{mol}^{-1}\right]$ molar molecular mass of fuel, $n^{d}[\mathrm{~mol}]$ substance amount of dry exhaust gases, $\mathrm{N}_{\mathrm{F}}[\mathrm{mol}]$ substance 
amount of consumed fuel and finally $y_{i}^{d}$ molar fraction of $i^{- \text {th }}$ pollutant in dry exhaust gases.

\section{Problem solution}

The observed problem and its solutions concern practical tests on vehicles in real operation, especially laboratory test on engine which is described below.

\subsection{Applied devices and methods}

\subsubsection{Laboratory test on the brake}

The tests in practical operation are carried out on vehicles T $8156 \times 6$ with engine Tatra T3-930-30, vehicles Tatra 8x8 with turbo engine Tatra T3-930-51 and on vehicles Land Rover Defender LR90DV with engine 300 TDI.

Tests to determine emissions under laboratory condition were carried out on the brake bench with electrical rotational brake Schenk 0-900 kW, operation in the revolution range $0-6000 \mathrm{rpm}$. As the primary fuel used was diesel F-54, which was in an alternative version of the comparative tests mixed with $2.5 \times 10-4$ volume parts of additive ENVIROX. The concentration of $\mathrm{CeO}_{2}$ in diesel fuel measured by atomic emissions spectrometry with inductively coupled plasma was $7.6 \mathrm{ppm} \mathrm{w} / \mathrm{w}$, which corresponds to the requirements of additive EnviroxTM suppliers [18].

For the actual test was used for four stoke diesel engine, naturally-aspirated engine Tatra T3-930-31 with direct injection, air-cooled, with engine capacity $1.9 \times 104 \mathrm{~cm}^{3}$. Rated engine power was $235 \mathrm{~kW} \pm 10 \%$ at speed $2.2 \times 103 \mathrm{rpm}$ with maximum torque $1.13 \times 103 \mathrm{~N}$ m at speed $1.4 \times 103 \pm 200 \mathrm{rpm}$.

Analyses of oil quality were carried out by methods based on physical and chemical principles that are to determine the concentration of wear metals, the methods of spectral analysis. Methods of morphology evaluation, the division of wear particles and methods of physic-chemical parameters. Method FTIR spectroscopy (Fourier Transform Infrared Spectroscopy), infrared spectroscopy with Fourier transformation belongs to spectral methods. It is suitable for determination of oil sample quality according to special methodology $[12,13]$. Another method is AES/RDE spectroscopy to detect wear metals. For evaluating the results is used method of trend analysis.

\subsubsection{Analysis of engine oil}

For tribodiagnostic analysis were used following devices and gauges. The device NICOLET AVAR 330, AES/RDE spectrometer SPECTROIL M, which is used for oil analysis in different specializations, is in versions $\mathrm{M}, \mathrm{M} / \mathrm{N}, \mathrm{M} / \mathrm{C}, \mathrm{M} / \mathrm{F}$ and $\mathrm{M} / \mathrm{R}$ a titrator METTLER-TOLEDO DL 25. Other used devices are analytical scales Sartorius Analytic A200/S and automatic viscometer AVS 310. Measurements with NICOLET AVAR 330 [14, 15] are done according to specific methodology supplied by its manufacturer. Measurements of infrared specter can be used to identify the type of engine oil or to determine amount of fuel in oil. These devices require a mathematical method of Fourier 
transformation, to obtain classical spectral record. FTIR spectrometers show a number of advantages. AES/RDE spectrometer SPECTROIL $M$ is designed to determine the volume of wear metals, contaminants and additives. The standard configuration of this device allows determination of volume of aluminum and other elements see [23]. Determination of stated elements in analyzes oil samples is crucial because it enables to detect a number of undesirable effects that may occur during the vehicle operation [16]. Its main advantages include the possibility of detecting defects, prediction of faults before they occur; reducing maintenance costs and reduce expensive downtime.

Automatic titrator METTLER TOLEDO DL 25 is a compact system for a titration analysis allowing automatic implementation and evaluation of titration. It is used to determine the number of total alkalinity TBN [17].

\subsubsection{Emission measurements}

Emission measurements were carried out by a combined device used for analyzing the composition of the fuel gas ECOM - JN. The volume of CxHy was identified by analyzer operating on principle of flame-ionization detection (FID). The principle uses phenomenon based on ionization of bond $\mathrm{C}-\mathrm{H}$. The monitored object- engine T3-930-31 is shown in Figure [24]. (Where 1- tested engine, 2- screen for heat dissipation, 3- clutch, 4- emission measuring point 1, 5- emission measuring point 2, 6- brake and its cooling).

\subsubsection{Verification of dimensional stability of selected engine components}

Before testing with NM 54 and NM with an additive special measuring of selected components of engine was carried out. It involved: Pistons with piston pins, piston rings, cylinders - cylinder inserts, cylinder heads and their intake and exhaust valves, exhaust pipes, injectors. The functionality of injection pump strokes was checked. Direct method with accuracy to a hundredth of millimeter was done to measure the components. Each size was measured three times in order to eliminate errors. This was done according to the methodology before and after the test with additive.

\subsubsection{Measurement of fuel consumption, economic benefits of additive ENVIROX}

For the test of fuel consumption and expression of its economic benefits special measurement methodology was processed. The measurements were scheduled at various load modes. It was decided to use modes with loads and speed that are most common in practice. Tests consisted of several stages. The first stage was preparation for the engine test; disassemble of the vehicle, measurement of selected components and assembly of the engine before testing. The second stage involved testing of transition to the fuel with additive. The third stage was cyclic tests. The end of testing included disassembly, re-measuring and evaluation. In individual stages were according to methodology carried out planned tribodiagnostics analysis of oil and emission measurements. 


\subsection{Outcomes and discussion}

\subsubsection{Oil analyses}

With the engine oil samples from laboratory were performed 31 tests according to the methodology of engine tests on brake. The aim was to confirm the correct type and quality of oil (see Figure 1).

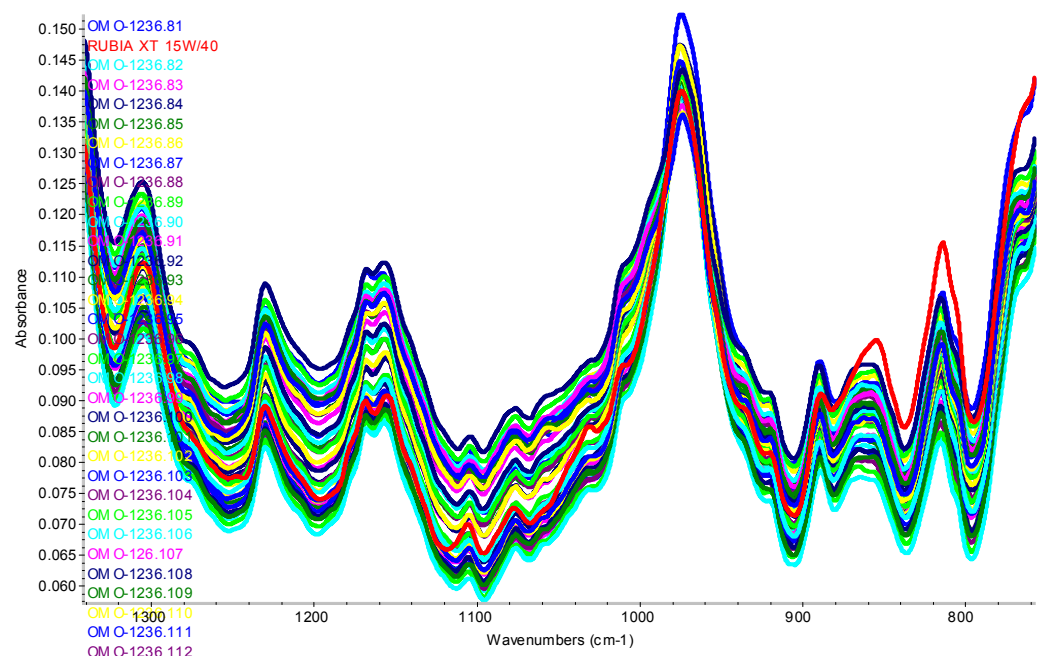

Figure 1: Spectra of oil samples taken from the engine.

\subsubsection{The test process on the engine bench}

The aim of the test was to verify the anticipated reduction in fuel consumption, reduce exhaust emissions, reduce deposits in the combustion chamber and in exhaust track and determine effects of additive Envirox to the engine condition. The test subject was a chemical product, additive Envirox, mixed with diesel F 54 in the ratio 1liter of Envirox to 4000 liters of diesel.

The transition tests included six sub-tests in two phases. In the first phase the engine worked on fuel F-54 and in the second phase it worked on EnviNM54, i.e. fuel F-54 with additive Envirox.

Cyclic tests included 31 repeated sub-tests in a wide range of speeds and loads with fuel EnviNM54. The cyclical test was considered as long term in total duration of $165 \mathrm{Mh}$. Each of the cyclical sub-tests consisted of Test $1 \mathrm{Mh}$ and Test $5 \mathrm{Mh}$, see [23] and a special tests (special measurements of engine components and tribodiagnostics and the influence of additive on storage and fuel tanks).

Analysis of result of transition tests - For analysis were used three methods of test result evaluation, namely comparing values of selected variables i.e. the power (Pe2200 or P2200red), fuel supply (Gh) and specific fuel consumption (mpe nebo mpred), obtained in the operation of engine on the brake bench with fuel F-54 and EnviNM54. 
Assessment by load testing - In the transition tests were obtained four load characteristics $(\mathrm{LCH})$ in two tests $5 \mathrm{Mh}$. $\mathrm{LCH}$ measurement results are shown in table [23]. Their curves for specific fuel consumption in Figure 2 have standard shape. The chart shows three pairs of curves corresponding to the speeds 1400 , 1600 and $1800 \mathrm{rpm}$. With smaller loads is difference between curves greater. With full load, i.e. proportional loading 1 , there is virtually no difference at any speed.

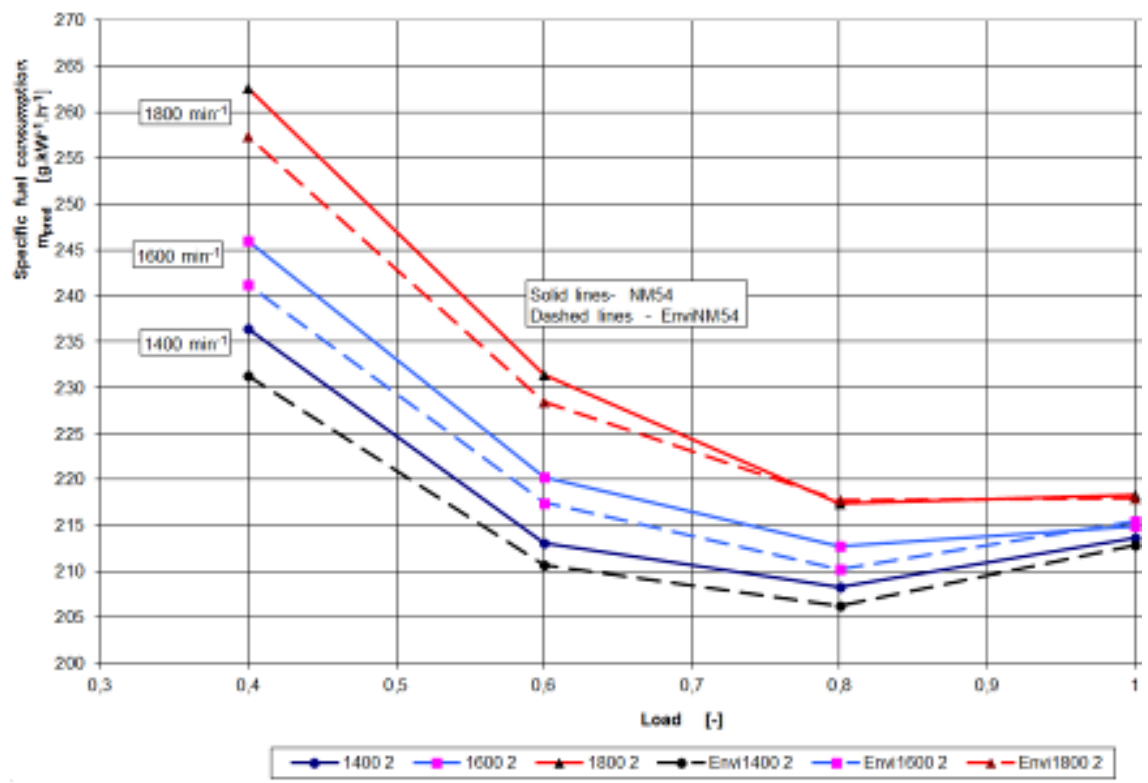

Figure 2: Transition test - impact of fuel changes on specific reduces consumption $\mathrm{m}_{\text {pred }}$.

The cross course of each pair of curves in Figure 2 shows, that running on fuel EnviNM54 has lower specific consumption compared to use of fuel F-54. Same conclusions as from the course of curves in Figure 2 can be made from values of percentage changes in specific consumption. At full load but also at 0.8 and at speed $1800 \mathrm{rpm}$, are changes less than $1 \%$. These are therefore practically negligible according to the measurement accuracy. It applies that the influence of additive Envirox is the most significant at lower engine loads.

Cyclic tests - The aim of these tests was to determine the effect of fuel EnviNM54 with additive on the quality of diesel engine activity in long operation. In the last Test $5 \mathrm{Mh}$, exhaust emissions were measured. Test $5 \mathrm{Mh}$ was chosen because its structure reflects operation of engines in real vehicles. The measurement of the load characteristics of $2 . \mathrm{LCH}$ were done at 1400, 1600 and $1800 \mathrm{rpm}$ and loads $100 \%, 80 \%, 60$ and $40 \%$; up to cooling and stopping of the engine [23]. 
Analysis of the cyclical test results - during these cyclical tests 31 Tests $5 \mathrm{Mh}$ were performed, which presents $155 \mathrm{Mh}$ engine activities at various revolutions and loads. There were four curves measured, see Figure 3, corresponding to four revolution modes, i.e. $1400,1600,1800$ and $2200 \mathrm{rpm}$. In the legend was used indication mpred with number indicating, respective engine revolutions. The fuel supply was maximal in each mode.

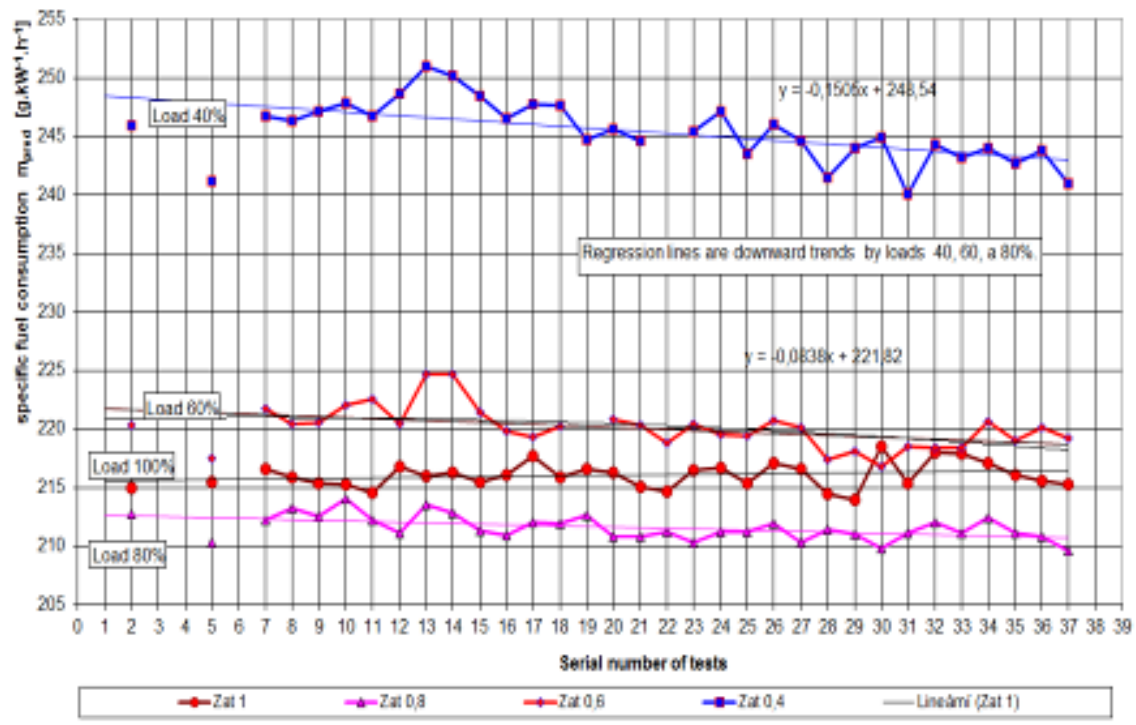

Figure 3: $\quad$ Specific fuel consumption at $1600 \mathrm{rpm}$ and loads.

During the cyclical tests gradually occurred decline in specific reduced consumption and therefore improvement in the quality of engine operation. Very clear is this trend at $40 \%$ load. The slopes of regression curves are smaller at higher loads (60 and 100\%).

Values listed are shown in table [23] and from there follows that the maximum fuel savings is $2.6 \%$ at a load of 0.4 and the engine speed of 1,600 $\mathrm{rpm}$. The higher load and the smaller decrease in specific fuel consumption at any speed is next result from diagram curves. At load 0,8 and greater, measured values fluctuate more or less around zero. This is probably error resulting from the accuracy of measurements.

The engine component measurements revealed that no change in weight of pistons occurred. Measurements were performed on cylinders zone A and zone B. Each of them was done three times without any change. When metering guides and valve cylinder heads, injectors, cylinder and piston injection pump the results showed identical values. No changes appeared that would relate to the operation of the engine using different type of fuel. 


\subsubsection{Mass balance of emissions}

Emission factors of i-th contaminant can be calculated in equation (3), which can be obtained by substitution of expression $\mathrm{n}^{d} \times\left(\mathrm{N}_{\mathrm{F}}\right)^{-1}$. The calculation of emission factors is based on equation describing fuel combustion and material balance of carbon, hydrogen, oxygen and nitrogen Furthermore, the substance amount of dry gas entering $N_{v}^{d}$ [mol] and exiting $\mathrm{n}^{\mathrm{d}}$ [mol] the combustion process was required (respectively the measured values of contaminant concentrations and oxygen. Fuel combustion in the engine was considered under simplified conditions in the absence of traces of polycyclic aromatic hydrocarbons $\mathrm{N}_{2} \mathrm{O}$, $\mathrm{NH}_{3}, \mathrm{SO}_{2}$ etc.

The theoretical calculation for molar fraction of unmonitored elements as well as conversion of concentrated elements to the moist air is done in [24]. Amount of fuel consumed can be calculated from the volume speed of streaming damp combustion gas in the sampling extension. For conversion of dry gaseous emission concentrations to damp gas concentration at the dynamic pressure measurement point is used by the Prandtl tube. Furthermore relations to calculate the concentration of water vapor and calculation of fuel composition were necessary. The calculation of emission factors was derived in equation for $\mu_{\mathrm{F}}=$ $\mathrm{M}_{\mathrm{F}} \times \mathrm{a}^{-1}[24]$.

$$
E f_{m}^{i}=\frac{y_{i}^{d} \times \frac{M_{i}}{\mu_{F}} \times\left[1+\omega \times\left(1-Y_{O_{2}}^{d}\right)\right]}{Y_{O_{2}}^{d}-y_{O_{2}}^{d}+\left(1-Y_{O_{2}}^{d}\right) \times \frac{y_{C O}^{d}}{2}-\left(1-\frac{Y_{O_{2}}^{d}}{2}\right) \times y_{N O_{2}}^{d}-\frac{y_{N O}^{d}}{2}+\left[a \times(1+\omega)-(1+a \omega) \times Y_{O_{2}}^{d}\right] \times y_{F}^{d}}
$$

Calculated values of emission factors under varying conditions of engine running in use of diesel fuel NM-54 without and with additive are presented in [24]. Hence it is clear, that when applying additive in comparison with pure diesel fuel there is a decrease of $\mathrm{C}_{\mathrm{x}} \mathrm{H}_{\mathrm{y}}$ emissions by approximately $12 \%$ and $\mathrm{NO}_{\mathrm{x}}$ emissions by about $8.5 \%$, whereas $\mathrm{CO}$ emissions have increased by around $23 \%$. Differences between values of emission factors of $\mathrm{CO}_{2}$ were insignificant for both investigated alternatives. Reduction of emission factor value for $\mathrm{CO}_{2}$ by $0.3 \%$ in case of the additive application roughly correlates with slightly reduced fuel consumption depending on engine operating conditions. Fuel savings up to $2.6 \%$ were observed when operating the engine with use of additives, if the $\mathrm{TM}_{R}$ $\in\langle 890 ; 1030\rangle \mathrm{N} \mathrm{m}, \mathrm{P} \in\langle 186 ; 214\rangle \mathrm{kW}$ and $\mathrm{f} \in\langle 1800,2200\rangle \mathrm{rpm}$.

The results are consistent with the data reported by the manufacturer exclusively for $\mathrm{C}_{\mathrm{x}} \mathrm{H}_{\mathrm{y}}, \mathrm{NO}_{\mathrm{x}}$, and $\mathrm{PM}$ emissions, while the contaminants of $\mathrm{CO}_{2}$ and $\mathrm{CO}$ are significantly different. The fact that declared reduction of fuel consumption and thus $\mathrm{CO}_{2}$ emissions was not detected and the emission factor for $\mathrm{CO}$ even markedly increased, can by partially explained by a short period of sampling after adding additives into the fuel. To exclude aging of tested engine as negative factor, additional verification test on a newer typo of engine are scheduled.

At the same time dependence of emission factors value was observed as function of reduced torque moment $T M_{\mathrm{R}}$, power $P$ and engine revolutions $f$. 
According to theoretical assumptions it can be stated, that most emissions after the initial increase slightly decline with increasing $T M_{R}$ and reach a minimum at about $180 \mathrm{~kW}$. The examples are figures illustrated in graphical dependence of emission factors value for $\mathrm{NO}_{\mathrm{x}}$ as function $T M_{R}$ in [24] and on the figure the course of $P M$ particles [7]. Format of trend line was evaluated by nonlinear regression of second degree polynomial, while the corresponding regression equation along with the value of reliability $R$ is included in the graph.

\section{Conclusions}

Conclusions from tribodiagnostics - according to the methodology of testing a number of measurements and analyses were done on samples. Measured values of individual indicators and their trends were compared with criteria from working conditions. The technical condition of engine tested on brake bench was throughout the testing very well. All indicators of tribotechnical diagnosis reflected usual use of diesel fuel used by ACR. The negative effect of additive Envirox used in fuel on the technical condition of engine was not demonstrated.

Conclusions from the cyclical test on the brake - the main criterion in cyclical tests are trends of observed variables. During the cyclical tests gradually occurred decline in specific reduced consumption and therefore improvement in the quality of engine operation mostly at lower load. At the lowest load which was $40 \%$ the decline of fuel consumption was approximately 2,6\%. With increasing engine speed the value of specific reduced fuel consumption increased, which appears as correct trend. The higher the load the smaller is the specific consumption reduction at any speed. At $80 \%$ load or higher, the measured values fluctuate around zero.

Assessment of additive quality - additive ENVIROX is dispensed in a volume ratio of 1:4000 to fuel F-54. Physic-chemical parameters of the fuel do not change significantly. The physic-chemical nature of additive Envirox limits its use in fuel and it is not recommended to be added into fuel long-term stored in tanks or in stored vehicles.

The assessment of engine components implies that the fuel mixed with Envirox has no significant impact on wear of engine components or limitation of carbon, it seen from Figure 4.

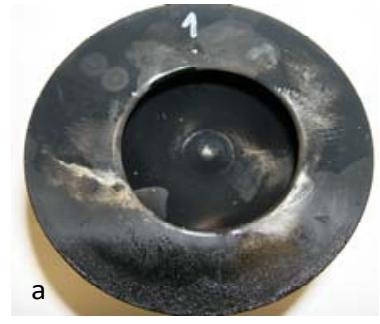

Figure 4: a) Piston after operation with F-54. with Envirox.

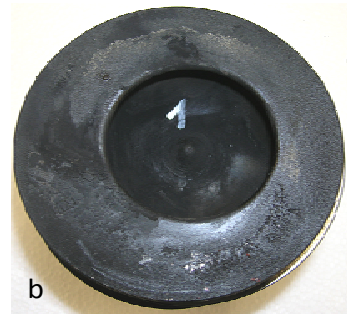

b) Piston after operation 
Evaluation of emission burden - It was established that the additive Envirox ${ }^{\mathrm{TM}}$ based on dispersed nanoparticles $\mathrm{CeO}_{2}$ decrease the value of emission factors for CxHy, by approximately $12.0 \%$ and for $\mathrm{NOx}$ by about $8.5 \%$. Additive manufacturer states, that declared reduction of $\mathrm{CO}_{2}$ corresponds with lower fuel consumption in interval $5-12 \%$, nevertheless this has not been demonstrated. Maximal fuel saving of around 3\% was found only under optimal conditions of engine operation, which corresponded to the $\mathrm{CO}_{2}$ emission decrease by only about $1 \%$.

It is still essential to verify disagreements between produced emissions of $\mathrm{CO}_{2}$ and $\mathrm{CO}$ and data given by additive manufacturer in some dependencies of emission factors on selected engine characteristics. The verification will be done by following tests on newer type of engine and after sufficiently long period of engine operating with additive Envirox ${ }^{\mathrm{TM}}$.

\section{References}

[1] Matejovsky, V. Automobile Fuel, [In Czech] Prague: Grada Publishing, 2005, p. 224. ISBN 80-247-0350-5.

[2] Lao, J. and Teixidó, O. Air quality model for Barcelona, Malta, 2011. In book Air pollution XIX. WIT Press. P. 25-36. ISBN 978-1-84564-528-1.

[3] Borrego, C., Cascao, P., Lopes, M., Amorim, J. H., Tavares, R., Rodrigues, V., Martins, J., Miranda, A. I., and Chrysoulakis, N. Impact of urban planning alternatives on air quality. Malta, 2011. In book Air pollution XIX. WIT Press. P. 13-24. ISBN 978-1-84564-528-1.

[4] Nagendra, S., Khare, M., Vijay, P. and Gulia, S. Performance evaluation of the ADMS- Urban model in predicting $\mathrm{PM}_{10}$ concentrations at the roadside in Chennai and Newcastle. Malta, 2011. In book of Air pollution XIX. WIT Press. P. 71 - 80. ISBN 978-1-84564-528-1.

[5] Krajcovic, M. Transport Construction I [Textbook] Brno, academic publishing CERM, 1998, p. 221. ISBN 80-214-1147-3.

[6] Rutter, J. C. et al. Public Transport and Car Use in Developing Country: Energy and Management Issues. Indian Journal of Transport Management. 1997, 21, (1), 89-96.

[7] Božek, F. et al. Emission of Particulate Matter While Applying the EnviroxTM Additive. In Proceedings of the 5th WSEAS International Conference on Waste Management, Water Pollution, Air Pollution, Indoor Climate. Iasi, Romania: WIT Press, 2011, p. 170 - 175. ISBN 978-1-61804012-1.

[8] Attfield, M. Envirox ${ }^{\text {TM }}$ Fuel-Borne Catalyst. Oxford: Oxonica, 2009. 49 p.

[9] Oxonica. Technical note 1. Diesel Fuel Additives and EnviroxTM Fuel Efficiency Additive. Oxford: Oxonica, 2008. 3 p.

[10] Singer, J. Implementation of tribodiagnostic analysis in armed forces. Proceeding book II. The Conference "Management of use and maintenance of vehicles and material". Brno, 2006.

[11] AOAP Oil Analysis Program [Presentation] Fort Lee, VA, USA, 2005, 85 sl. 
[12] Wilson, E.B.; Decius, J.C.; Cross, P.C. Molecular Vibrations, Dover, 1980.

[13] Brown, J.M. Molecular Spectroscopy, Oxford University Press, 1998.

[14] NICOLET CZ s.r.o.: Spektroskopic software Omnic 6. Technical documentation of FTIR spectrophotometer NICOLET AVATAR 330. Prague, 2003.

[15] ERSEPKE, Z.: Methods of laboratory analyses of oils. Handbook of Lubrication and Friction - internal documents of company SPECTRO Industrial Tribology Systems 1997.

[16] SPECTRO Inc.: SPECTROIL M OIL Analysis Spectrometers. Operations and User Maintenance Manual. Technická dokumentace k AES/RDE spektrofotometru SPECTROIL M. Littleton 2004.

[17] METTLER - TOLEDO AG: Bedienungsanleitung Titrator DL-21, DL-25. Technical documentation for the titrator METTLER-TOLEDO DL-25.

[18] Oxonica. Technical note 1. Diesel Fuel Additives and EnviroxTM Fuel Efficiency Additive. Oxford: Oxonica, 2008. 3 p.

[19] Wakefield, G. et al. Envirox ${ }^{\mathrm{TM}}$ Fuel-Borne Catalyst: Developing and Launching a Nano-Fuel Additive. Technology Analysis \& Strategic Management, 2008, 20, (1), 127-136.

[20] Knecht, W. Diesel Engine Development in View of Reduced Emission Standards. Energy, 2008, 33, (2), 264-271.

[21] Clerc, J., C. Catalytic Diesel Exhaust After-treatment. Applied Catalysis B: Environmental, 1996, 10, (1-3), 99-115.

[22] Roj, A., Karlsson, K. High Quality Diesel Fuel Reduces Emissions. In Fuel Reformulation, 1995, 46-52.

[23] Mares, J. et al. Annual report of ENVIROX project 2010. Brno, 2010, p. 100.

[24] Božek, F., Mares, J., Gavendova, H., and Huzlik, J. Emission of Selected Gas Pollutants in the Application of the Additive Envirox ${ }^{\mathrm{TM}}$. In Proceedings of the XIX ${ }^{\text {th }}$ Wessex International Conference on Modelling, Monitoring and Management of Air Pollution. Malta: WIT Press, 2011, p. 343-352. ISBN 978-1-84564-528-1. 